\title{
Behind the scenes of a learning agri-food value chain: lessons from action research
}

\author{
Charis Linda Braun ${ }^{1,2}$ (D) Vera Bitsch ${ }^{1} \cdot$ Anna Maria Häring ${ }^{2}$
}

Accepted: 29 May 2021 / Published online: 11 June 2021

(c) The Author(s) 2021

\begin{abstract}
The development of sustainable agri-food systems requires not only new academic knowledge, but also concrete social and organizational change in practice. This article reflects on the action research process that supported and explored the learning process in an emerging agri-food value chain in the Berlin-Brandenburg region in eastern Germany. The action research study involved value chain actors, academic researchers, and process facilitators in a learning network. By framing the network's learning and problem solving processes in concepts of organizational learning, lessons were drawn for researchers and value chain developers. The results underline the importance of process facilitation in a learning value chain to create a social space, in which the actors in the value chain can interact and find a common basis for collaboration. In the learning process, facilitators used an iterative design to consistently align learning activities with the needs of practitioners to ensure practical relevance. To establish new practices and partnerships, value chain actors challenged existing routines and developed new ideas and visions, while at the same time improving established practices within their organizations and along the entire value chain.
\end{abstract}

Keywords Action research · Organizational learning · Process facilitation · Grounded theory $\cdot$ Local and organic food

\section{Introduction}

The transformation towards more sustainability in many areas of society calls for collaborative learning; in which stakeholders question existing practices, as well as frames of reference and perspectives that they sometimes take for granted (Boström et al. 2018). One such area is the agri-food system, where the importance of creating shared knowledge and understanding to address sustainability challenges has

Charis Linda Braun

charis.braun@tum.de

Vera Bitsch

bitsch@tum.de

Anna Maria Häring

anna.haering@hnee.de

1 Technical University of Munich, TUM School of Management and School of Life Sciences, Chair of Economics of Horticulture and Landscaping, Alte Akademie 16, 85354 Freising, Germany

2 University for Sustainable Development Eberswalde, Unit of Policy and Markets in the Agri-Food-Sector, Schicklerstraße 5, 16225 Eberswalde, Germany been widely discussed in the literature (e.g., Batie 2008; Moschitz et al. 2015). Building effective and responsive agri-food systems is a complex social process that is centered around knowledge creation among all actors of a food value chain (e.g., Coughlan et al. 2016; Peterson 2009). During this process, the actors need to learn together, negotiate common goals, and develop and implement joint business models or other forms of partnerships that enable them to work together towards more sustainable systems (Peterson 2009).

This paper offers insights into a learning network that was formed to bring together a group of actors from the agri-food system - farmers, food processors, and traders - in the Berlin-Brandenburg region in eastern Germany. There is a high demand for local and organic food in the region, but structural issues in the agri-food system prevent local actors from benefitting from the potential for local capture of the value of that demand, particularly in the organic vegetable sector (Braun et al. 2018; Doernberg et al. 2016). The members of the learning network aimed to gain a better understanding of these issues, and to develop a sustainable agri-food value chain that benefits all actors involved equitably. 
The learning network was supported by a facilitation team of both academic researchers and staff members of a local advocacy group for organic agriculture. This facilitation team managed the learning process and provided the network members with access to the necessary resources, such as project infrastructure, training sessions, and other learning activities. Within the learning network, the activities were embedded in a case study that followed an action research approach. Action research provided a platform for the members to create knowledge and understanding regarding the issues at hand, by continuously discussing problems and possible solutions, experimenting with new practices, and reflecting on the outcomes. The first author of this article is a researcher in the facilitation team and was responsible for the research design and its implementation. With regard to the learning network, she was actively involved in the strategic planning of the process and engaged in the practical facilitation of network activities.

The present paper frames the collaborative learning and problem solving processes inherent in an emerging local agri-food value chain through theoretical concepts of organizational learning, and reflects on the action research process of the study. It offers a look behind the scenes of the learning network, focusing not on the details of the value chain, but on the strategies developed to enable collaborative learning and change in the network through action research. Since the establishment of the learning network, the process has led to a number of improvements in production and logistics, as well as the formation of partnerships and joint ventures in the region's organic vegetable sector. The experiences from the network can serve as an example of how organizational learning among stakeholders of local agri-food systems can be facilitated. The objectives of this article are, therefore, to illustrate the facilitation of the learning process, and to outline lessons learned, as recommendations for the development of other local agri-food value chains using similar participatory approaches.

\section{Collaborative learning through action research}

Action research brings together practice and research. It is not a distinct methodology, but rather a set of tools and methods that share a participatory orientation towards knowledge creation (Bradbury 2015). In action research, researchers work actively together with the people affected by a real-world problem instead of taking a more positivist and thus, more passive, observatory research approach. Action research is a collaborative learning effort, in that researchers effect change in the practitioners' world, and through this, are also able to personally experience how practitioners think and act in a particular situation. At the same time, practitioners learn to more systematically explore and address the issues identified in the learning process. Through the collaborative learning process, action research, thus, creates new knowledge for both academia and practice. This understanding of knowledge creation is rooted in the axiom "you cannot understand a system until you try to change it" - a notion that is based on the work of Lewin (1946), who pioneered applied research into organizational development (e.g., Schein 1996, p. 64).

In recent decades, action research has become an umbrella term for a number of different approaches aimed at organizational learning and development and, more generally, the improvement of complex social situations (e.g., Argyris and Schön 1989; Schein 1995; Shani and Coghlan 2019). Action research approaches have been used in agricultural research and development since the 1970s (Whyte 1991) and have more recently been applied to the study of local agri-food systems (e.g., Block et al 2008; Coughlan et al. 2016; Conner et al. 2010; Guzmán et al. 2013; Swords 2019). What the latter studies have in common is that action researchers brought together multiple actors and helped to manage the complexity of the problems under investigation by facilitating collaborative learning - both to create new knowledge, and to improve the participating actors' situation. For example, Coughlan et al. (2016) developed a specific action research approach they dubbed "action learning research" to explore and support several learning networks among small-scale food producers in different parts of Europe. Within these networks, food producers learn together to explore issues and create new knowledge that they later implement and exploit individually in their own organizations (Coughlan et al. 2016). Other action research studies specifically addressed the development of local agrifood value chains. Guzmán et al. (2013), for example, presented several case studies from the Spanish organic farming sector where action research was used to explore and support local networks of food producers working together to establish collaborative models for the production and marketing of organic food products.

The present paper adds to the discussion of change through collaborative learning in the agri-food sector by drawing on theoretical concepts of organizational learning as a lens for exploring the process of learning and change in a network of value chain actors (Fig. 1). The design of the action research study also included a component of process facilitation aimed at creating an environment where effective decision making and problem solving can take place, in the sense of double-loop learning (Argyris 1995).

As process facilitators, the action researchers were not mere observers, neutral and detached from the subject of the study. Rather, they were immersed in the setting they were studying and became actors themselves as they supported participants in achieving their goals. With regard to 
Fig. 1 Action research applied to the present study's learning network

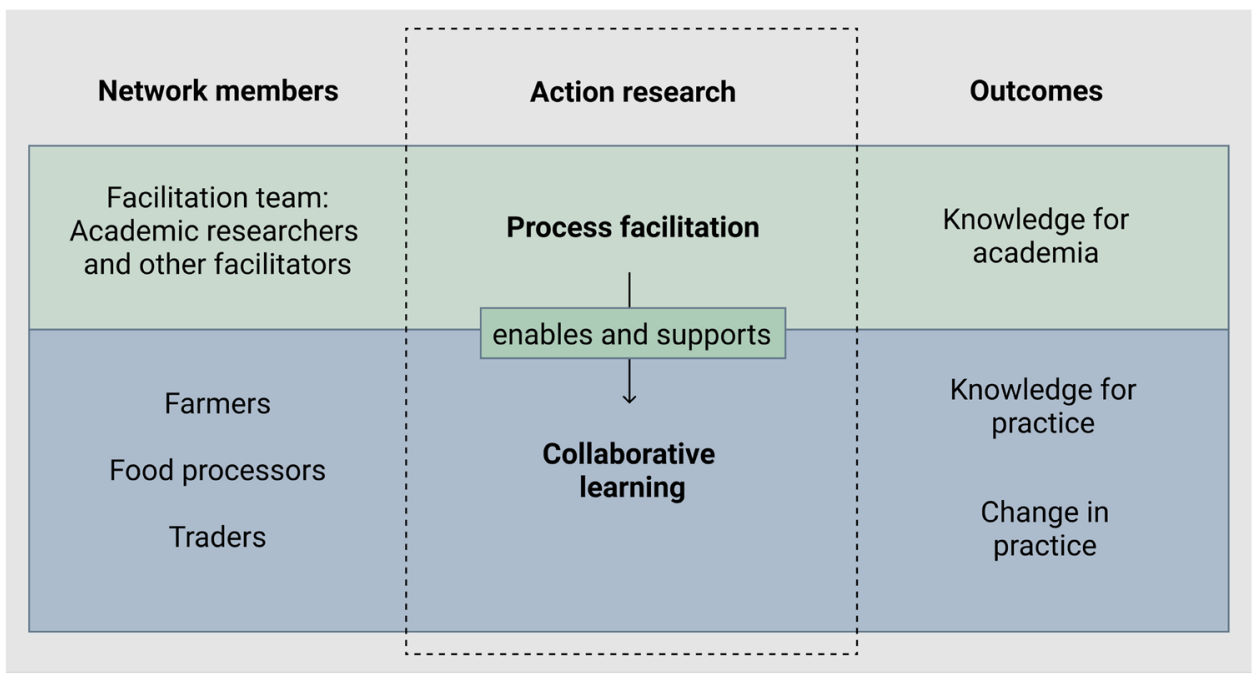

the concrete goals of the network, however, the facilitation team was neutral and did not pursue its own agenda. Rather, the team supported practitioners in making well-informed decisions and implementing them.

The study followed a strand of action research that is concerned with issues of management and organizational studies (e.g., Eden and Huxham 1996; Shani and Coghlan 2019) and is situated in the context of the agri-food sector in Western Europe. The learning network is not a social movement that pursues a political agenda in the sense of "activist research" (Hale 2001) where researchers work with affected people to overcome social justice issues. Rather, the purpose of the network is the improvement of the professional practice of the participating actors, along with the co-generation of practical and academic knowledge on the same topic.

\section{Process facilitation}

In an action research study, researchers act as facilitators for learning and change processes in organizations, networks, or other social settings. In the literature, the role of such facilitators is commonly discussed under the generic term of intermediation (e.g., Agogué et al. 2017; Howells 2006; Klerkx and Leeuwis 2009; Kivimaa et al. 2019). Intermediation is performed by individuals or organizations that support the interaction between the stakeholders of a particular project, problem, or process. They act, for example, as innovation brokers that help stakeholders to develop steps towards transformational change (Klerkx and Leeuwis 2009). Their exact functions vary depending on the situation and context in which they work. In practice, they may bring actors together, manage their interaction, or provide them with resources necessary to reach a common goal (Kanda et al. 2020).
Facilitation in action research can be described based on Schein's (1995) model of "process consultation", where a facilitator works with a group of people to solve a practical problem. Process consultation differs from other common models of consulting, which rely on a consultant's expert advice or special diagnostic capability to solve a problem for a client. By contrast, a process consultant is a facilitator who helps to create conditions that allow actors to uncover and address problems themselves based on their needs and objectives. In Schein's terms, “the client owns the problem and the solution, but consultant and client jointly own the inquiry process that will reveal what the correct next step might be" (Schein 1997, p. 207).

\section{Organizational learning}

Organizational learning can be defined as a process, in which people or organizations detect a problem caused by a discrepancy between the intended and actual outcomes of their actions, and correct it (Argyris and Schön 1996). This abstract understanding of learning is based on the idea that people have internal representations of reality, often called mental models, which they use to reason about the world and take action (e.g., Gentner and Stevens 2014; Senge 1990). Mental models are tacit knowledge structures that can be understood using Argyris and Schön's (1996) theory of action, which distinguishes between espoused theory and theory-in-use. Espoused theory describes people's intentions-or how they think they act-while theory-in-use manifests itself in their actual behavior. According to Argyris and Schön (1996), when organizational learning takes place, people better align their intentions with the consequences of their actions. Through reflection, practitioners can develop new knowledge about their work and improve future practice 
(Schön 1983). Similarly, Senge (1990) emphasizes the need for reflection to become more aware of one's own mental models, and the need for inquiry through interaction with others when dealing with complex issues.

According to Argyris and Schön (1996), there are two modes of organizational learning - single- and doubleloop learning. Single-loop learning refers to a situation, in which people or organizations improve their existing procedures but the mental models that guided the initial actions remain unchanged. By contrast, double-loop learning occurs when not only actions are changed, but the underlying mental models that determine them are also altered. Thus, a given problem is addressed by challenging the basic assumptions, objectives, or values that caused the problem in the first place. An environment that enables double-loop learning helps people to generate valid and reliable information, make informed decisions, develop commitment to implementing those decisions, and monitor outcomes to detect and correct errors in their behavior (Argyris 1995). The concept of double-loop learning has been used in a number of recent studies on learning related to major challenges or changes in agricultural and food systems. These include, in particular, studies concerned with behavioral change to reduce agriculture's environmental impacts (e.g., Inman et al. 2018; Tengberg and Valencia 2018), and studies that address how new practices can be established in agricultural production and management (e.g., Eshuis and Stuiver 2005; Melin and Barth 2018).

\section{From data gathering to conceptualization in the action research process}

The study integrated a grounded theory analysis into the action research process (Fig. 2). By planning, implementing and reflecting on learning activities, data were continuously collected, analyzed, and conceptualized through the grounded theory approach. The results of the analysis formed the basis for academic knowledge and were also used in the planning and preparation of subsequent learning activities.

Grounded theory, originally introduced by Glaser and Strauss (1967), is a qualitative research methodology for systematically generating theory through abduction in an iterative process of data collection and analysis (Corbin and Strauss 2015; Richardson and Kramer 2006). It is widely used to investigate social practices and processes, and has gained recognition in agri-food business research through Bitsch (2005) and Peterson (2011). In the present paper, the grounded theory approach was employed to distill lessons learned during the study's iterative action research process. Rather than looking at the value chain as such, the analysis was aimed at tracking the strategies employed in the facilitation of the network and documenting the unfolding of the learning and problem-solving processes.

A special feature of action research is that data are collected about what people say or do when they are confronted with a need for action. Data from action research are reliable and timely, in the sense that they are collected at the moment an action takes place, as opposed to being a description of a past situation (Huxham 2003). In the terms of Argyris and
Fig. 2 Grounded theory analysis embedded in the study's action research process

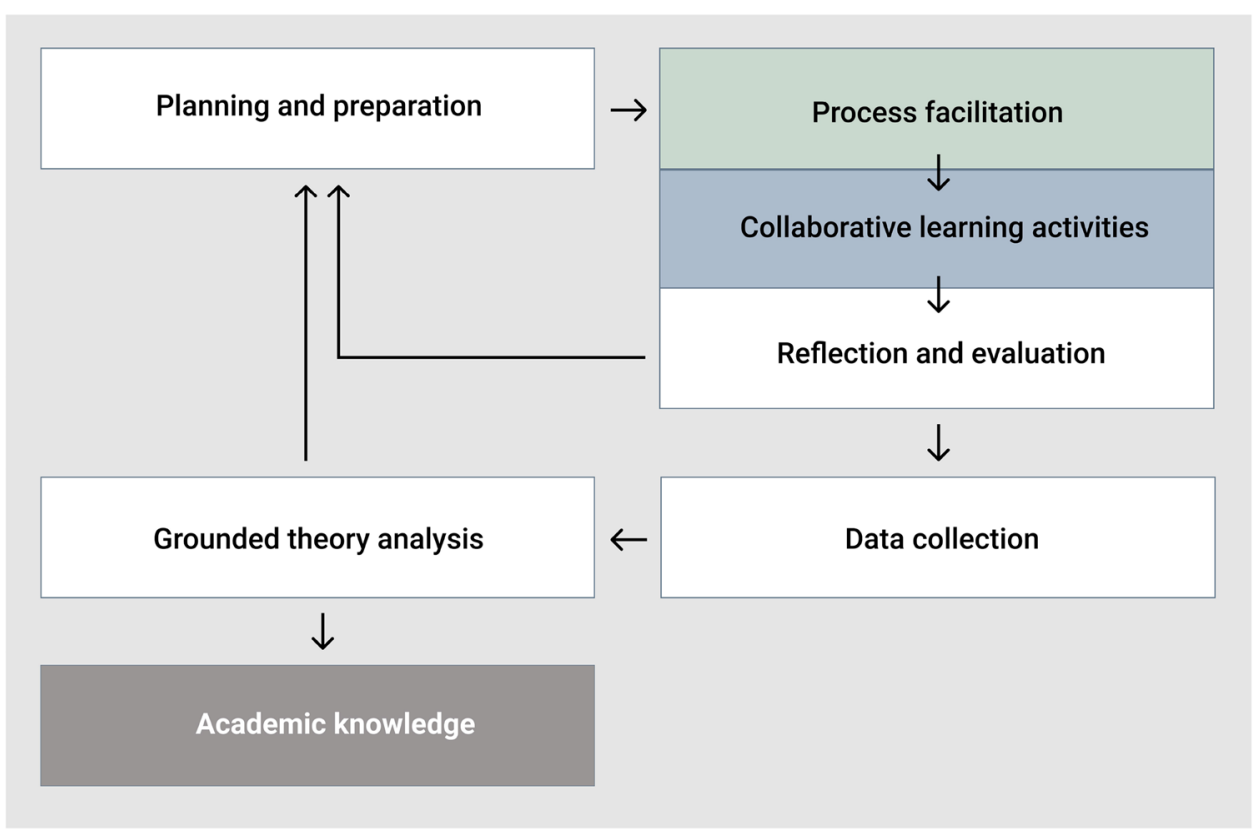


Schön (1996), action research has the potential to uncover theories-in-use, because it focuses on the actual behavior of actors rather than on the espoused theory they articulate, for example, in an interview. The combination of action research and grounded theory, therefore, generates knowledge that is not only grounded in data, but is also "grounded in action" (Eden and Huxham 1996, p. 82).

Data collection and analysis took place between November 2017 and June 2020. Data were obtained throughout the action research process from participant observation at workshops and business meetings, qualitative interviews and informal conversations with value chain actors, and internal process planning and reflection sessions of the facilitation team (Table 1). Data consisted of field notes, video, and audio transcripts; as well as other material collected in meetings and workshops, such as flipchart sheets or drawings produced by participants.

In the grounded theory approach, data analysis is a recursive process of constant comparison, where researchers look for similarities and differences in data (Corbin and Strauss 2015). During the analysis, the raw data are systematically broken down and compared, and recurring concepts are extracted, labeled, and annotated in a process known as open coding. Conceptually similar codes are then grouped together, refined, and abstracted into categories. Throughout the process, researchers move back and forth between data collection, coding, and category (re)conceptualization.

The analysis took place in three recursive steps. In the first step, the data collected in the context of action research was reviewed and systematically organized. This pool of data was the basis for open coding, in which codes were assigned to text fragments and other types of data (such as photographs). During this process, as new codes were created, other codes were merged, renamed or deleted through constant comparison of new data to previously created codes. The analysis process was supported by Atlas.ti, a software package for qualitative data analysis, which provides tools for managing, labeling, and annotating unstructured data (Friese 2019). While the analysis was initially open and exploratory, the focus was narrowed as the learning process progressed. Thus, after the initial experiences with the action research process, only those parts of workshops and meetings that were relevant to the discussion of the learning process were included in the coding.

Second, the categories created in the first step were further refined. Visual mapping techniques with paper cards and pinboards were used to connect categories and identify patterns that emerged during the learning process. Newly emergent categories were regularly cross-validated within the facilitation team and with input from other network members. The final result of the analysis was a hierarchy of categories and subcategories which reflected the facilitated learning processes (Fig. 3).

As a third step, the categories derived from the grounded theory analysis were interpreted in the context of organizational learning theory. Based on comparing the results to the existing literature and discussions among the authors, lessons learned were derived for the development of emerging agri-food value chains.

\section{Case description: the learning network}

This section illustrates the context of the present action research study and details the collaborative problem solving process that is at its core. The study is set in the

Table 1 Overview of data collected in the learning process

\begin{tabular}{ll}
\hline Data collection & Data sources \\
\hline Qualitative interviews: & Current situation of the vegetable sector: \\
Audio transcripts, photos, field notes & 18 in-depth interviews with practitioners: farmers, traders, food processors (2018) \\
& Evaluation of the learning process: \\
& 12 in-depth interviews with practitioners (2019) \\
& 2 group interviews with practitioners (2020) \\
& Building and planning of the learning network: \\
Participant observation, workshop and meeting & 3 workshops with practitioners (2017, 2018) \\
documentation: & Strategic business development and reflection (individual farms): \\
Field notes, video and audio recordings, photos & 2 workshops with farmers (2018, 2019) \\
and other material produced at workshops and & Strategic value chain development and reflection (value chain): \\
meetings & 20 workshops and business meetings with small groups of practitioners (2018, 2019, 2020) \\
& Reflection and planning meetings (facilitation team): \\
& 11 internal workshops of the facilitation team (2017, 2018, 2019, 2020) \\
& Informal conversations with network members: \\
Records of conversations: & Workshops and field trips with practitioners, weekly meetings of the facilitation team, and \\
Field notes & evaluation meetings with external consultants and mentors \\
& Field notes from meetings and phone conversations \\
& Email archive \\
\hline
\end{tabular}


Fig. 3 Coding frame developed in the grounded theory analysis

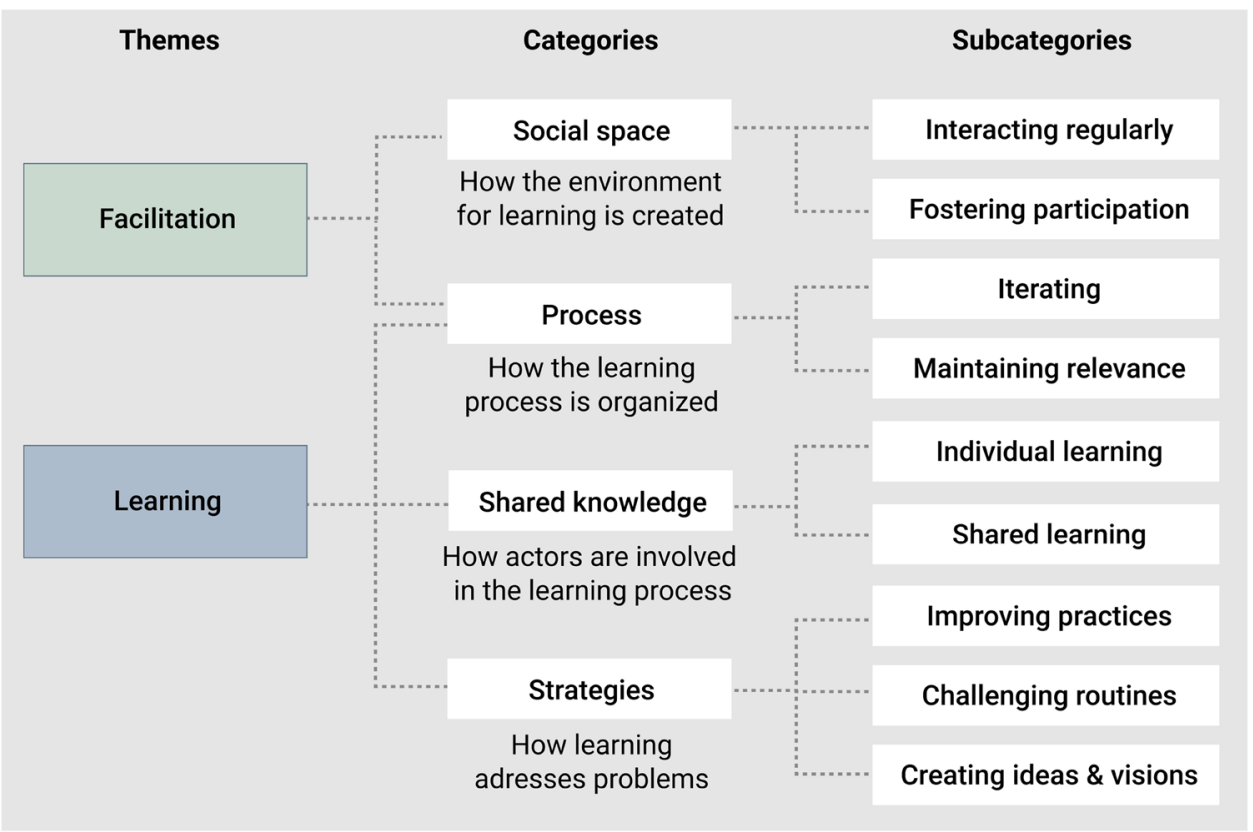

Berlin-Brandenburg region, which consists of Berlin, a city of 3.8 million people, and the surrounding state of Brandenburg, a largely rural region dominated by agriculture. In the metropolitan area of Berlin, there is an increasing demand for organic food, both in retail and public catering, driven by consumer interest and by policies promoting sustainable procurement practices (Braun et al. 2018; Doernberg et al. 2016). While organic farming in the surrounding state of Brandenburg has also increased, a number of structural issues in the agri-food sector prevent local actors from using the potential. The cultivation area for organic vegetables is relatively low compared to adjacent regions, and there is little exchange or coordination among the various actors of the sector. Many farms used direct marketing and there were some individual partnerships between local organic wholesalers and farms, but hardly any distribution via mid-sized marketing channels (Braun et al. 2018).

Through public announcements and personal invitations, the advocacy group brought together various practitioners from the region to address the problems of the local agrifood sector. Participants included, for example, farmers who were looking for better distribution channels or wanted to diversify their operations, but also processing and trading companies interested in sourcing organic products locally. After several meetings and workshops, the network was formed to work towards a better understanding of the issues and develop solutions. To support the learning process and generate academic knowledge about the issues, researchers from a local university became involved. The activities of the learning network were supported by grants from the European Union and the state of Brandenburg.
The network included 22 farms, food processors and trading companies. Most of the actors did not have previous business relations and many did not know each other personally. All network members were located within a radius of about $100 \mathrm{~km}$ around the city of Berlin. The network included both start-ups and established organizations, with different capabilities in terms of resources and expertise. Some of the food businesses were certified organic, others were not certified yet. Some farms had produced organic vegetables for many years, some wanted to get into vegetable production. The range of participants was also diverse in terms of age and gender. The heterogeneity of the actors meant that many contexts, concerns and interests had to be reconciled during the collaborative learning process.

The process was supported by a four-person facilitation team which included academic researchers and staff from the agricultural advocacy group. They were an interdisciplinary team that brought together people with professional backgrounds in practical agriculture, agribusiness, food economics, and communication sciences, some of which had additional qualifications in group dynamics and coaching. The team's tasks included network building, process facilitation, and organizing targeted consulting and training activities. All of these efforts were part of the action research study and were designed to generate concrete applicable knowledge for practitioners as well as academic knowledge about the process in which they participated. The facilitation team's role in the learning process was not primarily to provide expertise based on their domain knowledge but to guide the process in the sense of process consultation (Schein 1995). For specific expertise, external consultants were brought in as needed. 
The process was agile and flexible, in the sense that the final goal and the way to get there were not set from the beginning. Rather, there was an iterative planning process in which a series of consecutive phases were developed. Based on the outcome of one phase, the facilitation team planned the subsequent phase, together with the network members. Each phase was focused on a particular research question from which goals and activities were derived (Table 2). The activities of one phase were not necessarily completed with the start of the next phase. Some activities were continued throughout the study.

\section{Phase 1: Exploring the initial situation}

In the first phase, the network members discussed their needs and interests, defined common goals, and committed themselves to the collaborative learning process. They explored the issues of the organic vegetable sector in the region in several workshops, which also involved stakeholders from outside the network, such as industry experts, agricultural consultants, and policy makers. The learning activities in this phase included both group-based and individual inquiries into the actors' current situations, and workshops in which the outcomes of the research were discussed. These activities enabled the network members to get deeper insights into the current situation of the sector, to assess the potential for local value creation, and to identify specific issues to be addressed in subsequent phases.

\section{Phase 2: Empowering value chain actors}

The second phase of the action research study focused on empowering value chain actors to better understand their individual business situations and practices, and-on a higher level-to develop awareness of why they do what they do. During this phase, several group-based learning activities were facilitated, including a series of workshops on business development, farmer field schools on cultivating organic vegetables, and study trips to visit and learn from established operations in other regions. Farmers also received individual consulting and mentoring to address specific questions of organic cultivation, and to support experimentation with new practices.

As a result of the second phase, several farmers reoriented their operations towards larger-scale vegetable production, and some invested in new production technology and storage infrastructure. Others left the network to pursue other business strategies as they gained an improved understanding of their business situations. In parallel to the individual development of practitioners and their organizations, initial ideas of how to support value chain collaboration developed. To this end, meetings with market actors from outside the innovation network were facilitated to identify business opportunities and help create greater market transparency for participants. These activities later became the focus of the third phase of the action research study.

\section{Phase 3: Learning to collaborate}

In the third phase, a year-long strategy process was facilitated to identify possible areas of collaboration, and to develop values-based value chains. In such value chains, small and midscale farmers work together with other food businesses to produce and market sustainable food products at scale (Stevenson et al. 2011). Values-based value chains focus on both the values associated with the product (such as local and organic) and the values associated with the business relationships within the chain (such as joint decision-making and fair profits).

Learning activities in this phase included workshops for developing common visions and ideas, and meetings for establishing joint business models. In addition, the participants carried out experiments that explored, for example, the potential for collaboration between farmers and processors in terms of logistics and information sharing. These experiments ultimately resulted in new supply relationships, actual collaboration in production and marketing, and the formation of new joint enterprises among different value chain actors.

Each of the three phases of the learning process involved the value chain actors in various activities of inquiry and experimentation - ranging from group-based learning activities in workshops, to practical experiments in which they explored new practices and new ways of working together. Learning activities were often supported by visual methods, e.g., collaging, aimed to visualize the perspectives and the tacit knowledge of network members on issues related to both their individual business situations and to the value chain in general (Fig. 4). Experimenting meant that the practitioners drew from their new knowledge, applied it in practice, and then reflected on the outcomes. The spectrum of experiments ranged from individual trials (e.g., trying out new production processes and cultivation methods) to more extensive ventures (e.g., negotiating the founding of a joint enterprise between several actors). Reflection took place, for example, in workshops and in individual meetings between practitioners and facilitators. Over time, a repertoire of knowledge, experience and skills, as well as common ideas and visions emerged that eventually led to new forms of partnerships among value chain actors.

\section{Lessons from the learning value chain}

This part of the paper outlines lessons learned from establishing a learning value chain as a result of linking process facilitation with organizational learning concepts, embedded 


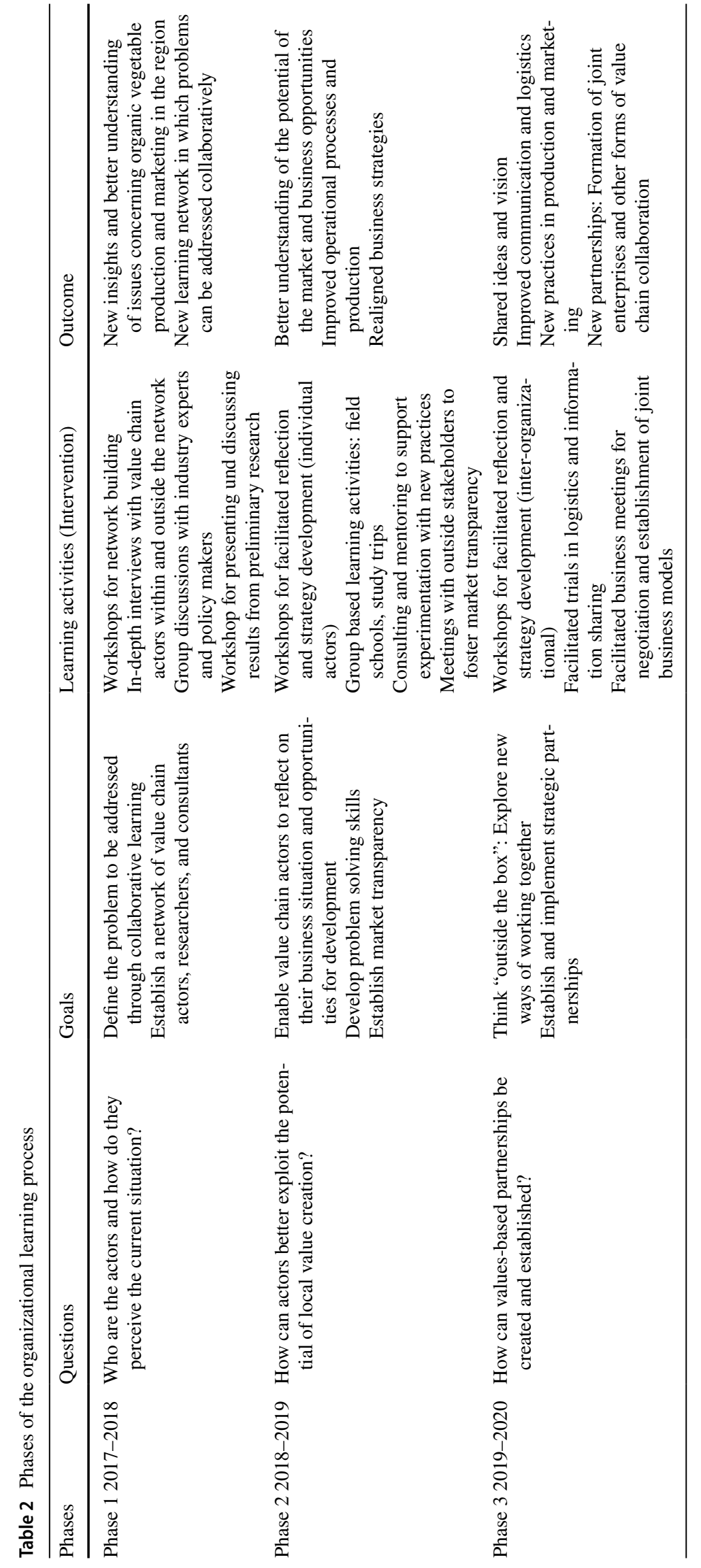



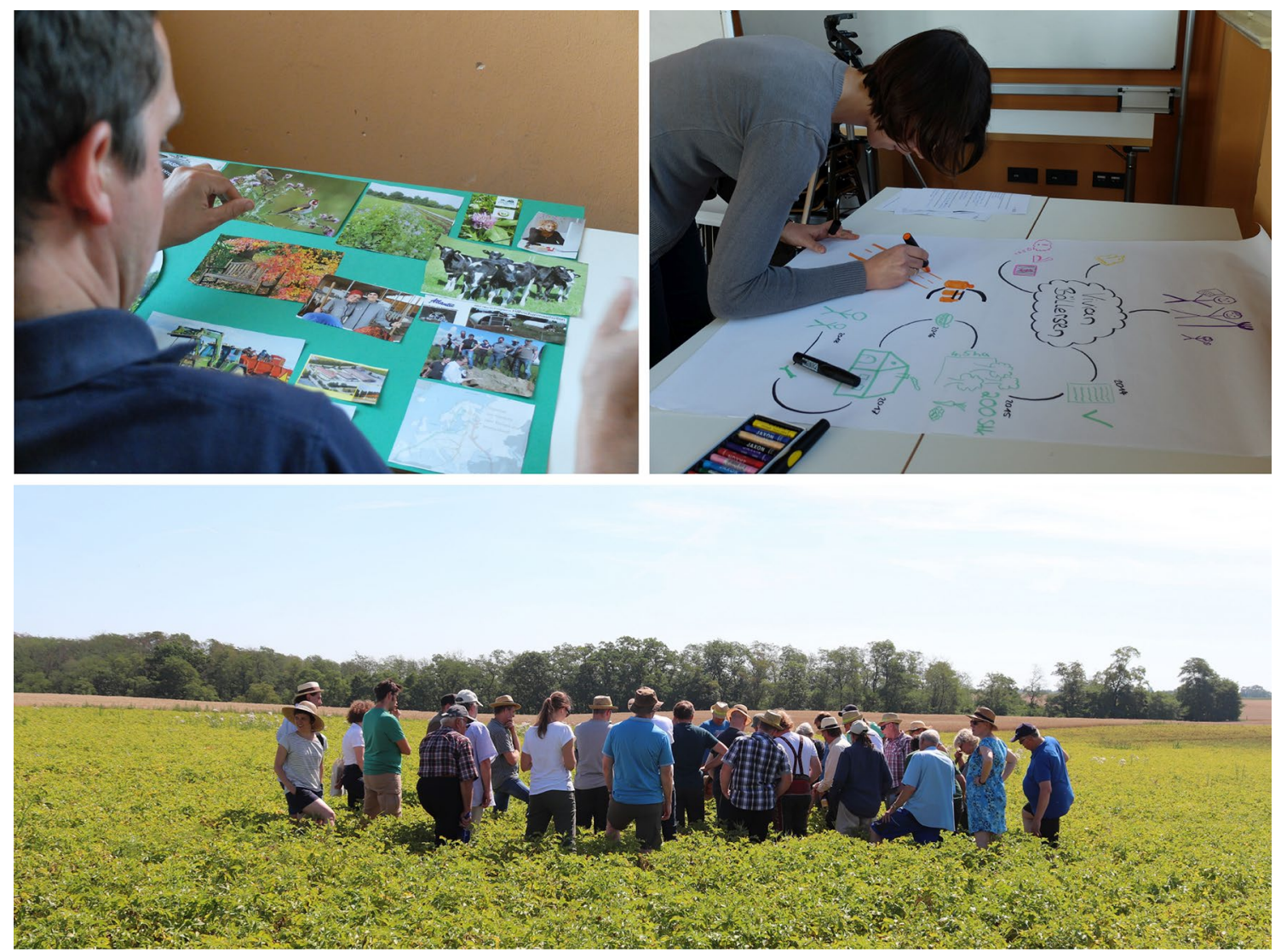

Fig. 4 Examples of learning situations in the network: collaging, mind mapping, and practical training

Fig. 5 Process overview: facilitation, organizational learning, and action research
Facilitation creates space for collaborative learning among value chain actors.

Learning agri-food value chain - built on learning in individuals, in organizations, and across the entire chain.

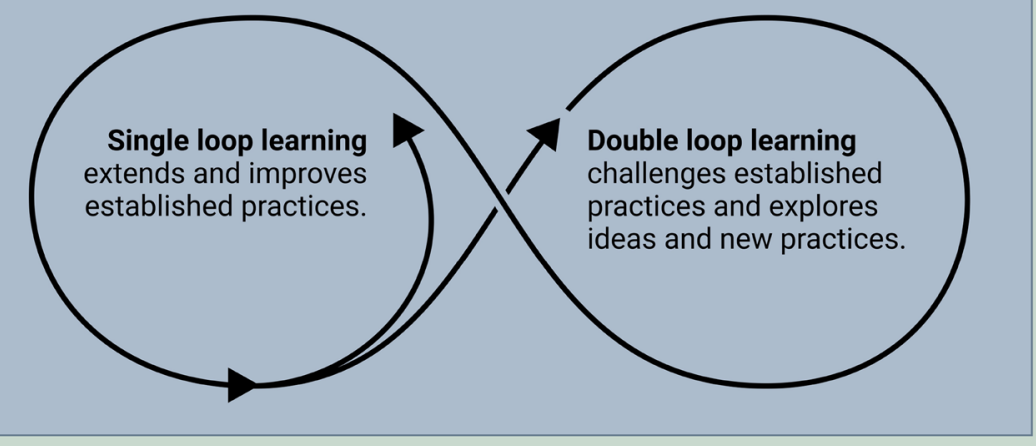

Action research investigates and supports the development of agri-food value chains. 
in an action research approach (Fig. 5). These lessons can be built upon for designing and implementing collaborative learning processes to support the development of local agrifood value chains, as well as for the use of action research in this context.

\section{Social space}

The starting point of the learning network were structural problems in the local organic vegetable sector, identified in the initial phase of the collaborative learning process. Problems included, for example, a lack of processing facilities and distribution channels for supplying the urban center with regional produce, and a lack of know-how, especially with regard to organic cultivation methods and the change in climatic conditions in the region. In addition, there was little exchange among actors in the sector. The network addressed these issues by bringing actors together and providing them with a learning environment to develop common understanding, from which they could work together to develop solutions. Within the network, the role of the facilitation team can be understood as that of an intermediary that supports social interaction between stakeholders. As defined by Kivimaa et al. (2019), the key functions of a process intermediary are to develop links between different actors and to support their interactions, in order to advance a particular innovation or transformation process.

Based on the problems and needs of network members, the facilitation team designed the program for the learning network and organized its activities. Network members took part in workshops and seminars, went on field trips, and established working groups around specific topics. The social space that resulted from these interactions was identified as one of the categories in the grounded theory analysis. It was derived from a metaphor used by members of the facilitation team when describing their work:

What we do is we create a space where you [the value chain actors] can come together and work on your problems so that something new can emerge. Our work is guided by what you need.

(Member of the facilitation team, in a 2017 workshop)

These regular opportunities for social interaction provided a physical space for collaborative learning, but also for getting to know each other and for building trust among the participants. Trusting relationships are a prerequisite for collaboration of any form, whether for developing a shared understanding of an issue or for building partnerships (Vangen and Huxham 2003). This applies to relationships among practitioners as well as relationships between participants and facilitators (Shani and Coghlan 2019).

The facilitation team designed the process from the outset with a focus on trust-building. On a formal level, there were agreements on the confidentiality of information disclosed by participants, for instance at workshops where internals of each company were discussed. On a practical level, participants were encouraged to open up to each other and talk about their expectations, their ideas, and the issues they were facing. By recognizing common problems and goals, they developed a sense of "being in this together". Over time, the actors gained more confidence in dealing with each other and formed a solid basis for communication. At this point, the facilitation team shifted the focus to sustaining the existing relationships by supporting communication and negotiations, maintaining transparency among participants, and fostering joint ownership in the process.

Lesson \#1: In a learning value chain, process facilitators create a social space to support regular interactions among value chain actors. The facilitators foster an environment of openness and transparency, in which all actors can participate in a collaborative process of learning and problem solving.

\section{Facilitating the learning process}

The learning network's facilitation team were tasked with enabling a heterogeneous group of value chain actors to harness the potential of local value creation. This objective can be understood as a "situation with a high degree of the unknown” (Agogué et al. 2017, p. 21), which involves a complex and ill-defined problem that has no definite solution and can only be addressed by intermediation-by bringing the stakeholders of the issue together in an exploratory process. To deal with the uncertainty, the learning and problem solving process within the network was designed as an iterative cycle of planning, acting, and reflecting.

The iterative design of the process is visible in the three major phases of the learning process but also in the individual interventions within each phase. The interventions of the first phase were developed on the basis of the goals, interests and needs of the value chain actors, which were jointly identified at the starting point of the process. During the first phase, the learning activities were further developed through regular reflection and evaluation within the facilitation team and together with value chain actors. The subsequent phases were planned, carried out and evaluated using the same cycle. Through this iterative approach of process facilitation, the activities of the learning network were gradually adapted to the needs of the actors in the value chain, which ensured the relevance for practice.

According to Schein (1995), a learning process and its interventions have to be developed jointly by practitioners and facilitators, based on the problems of practice. Hence, one challenge for the facilitation team was to continually involve the value chain actors in the iterative (re)design 
of the process. While the practitioners were interested in the tangible outcomes of the learning network, some were reluctant to participate in the activities of inquiry and reflection that were part of the process - which they perceived as time-consuming and cumbersome. Similar issues were highlighted by Ingram et al. (2020) in an analysis of agricultural co-innovation, where facilitators also described keeping agri-food practitioners involved in processes of collaborative learning as a major challenge.

In the present study, the facilitation team was able to address this issue by designing interventions in such a way that they always contained a component that promised immediate benefits to practitioners. For example, reflection activities were combined with seminars that provided actors with practical, immediately useful information, such as knowledge on cultivation methods or current market insights. In addition, the facilitators identified and supported particularly enthusiastic and well-connected actors who took on the role of "champions" of the learning network and promoted the development of the value chain on the basis of their own intrinsic motivation. For example, one farmer had the idea of working with other farmers to bundle produce for marketing through retailers. The facilitation team organized meetings where this farmer could further develop his idea together with other interested actors from the network. Later, the facilitation team supported product development, price negotiations, and conducting a test run with a major retailer.

Managing the learning process required both domain knowledge and methodological capabilities. Their professional backgrounds in farming or agribusiness and a thorough understanding of the local agri-food sector helped the facilitators to interpret the requirements, issues, and ideas articulated by value chain actors. In addition, their training in systemic coaching and group dynamics helped with preparing and facilitating events and negotiations, bringing about decisions, and mediating conflicts. In their work, they drew heavily on techniques of visualization, ideation, and reflection. A member of the facilitation team described what enabled her to align the learning process with the requirements of practice as follows:

My practical training [in farming] and my studies [in agribusiness] are very helpful in this respect. This really helps me to understand the practitioners' needs and their ideas to shape the process. [...] It is also important to know the set of methods used in process facilitation. This does not only mean to be able to facilitate a meeting. It also means to see which methods I can use to create deeper insights and to get the best out of these meetings for everyone.

(Member of the facilitation team, in a 2019 reflection meeting)
Not all of these competencies were combined in a single person. Rather, they were distributed among team members working closely together, which allowed for a division of tasks and specialization among the facilitators. For example, one person focused on ensuring rigorous research, while another developed training activities or facilitated the process of founding the joint enterprise. Working in a team also enabled facilitators to jointly reflect on their work and improve their own practice.

Lesson \#2: The facilitation of the learning process requires iterative design to gradually address a complex problem that involves many different perspectives and interests of value chain actors. The process should be (re)oriented continually based on the needs of the actors to ensure its practical relevance.

\section{Shared knowledge and understanding}

The present results indicate that a learning value chain has to consider learning by individual practitioners and their organizations as well as the value chain as a whole. During the value chain development, there was a strong interaction between intra- and inter-organizational learning (Holmqvist 2003). For example, value chain actors needed to develop a solid understanding of their companies' individual situations (intra-organizational) to assess the potential for collaboration along the value chain. Based on this, they could then develop strategic partnerships with other value chain actors (inter-organizational). A process facilitator described her experience with managing the learning process in the value chain as follows:

I have to keep an eye on the individual practitioners' issues and at the same time focus on the common goal and strategic direction [of the value chain], i.e., I have to keep switching between the bird's eye view and the frog's eye view.

(Member of the facilitation team, in a 2019 discussion with other facilitators)

The learning network provided the setting in which the participants could come together to develop shared knowledge and understanding. At the beginning of the process, the main focus was to explore the problems of the local agri-food sector and, on this basis, to define common goals for value chain cooperation. Later, the focus turned to the concrete coordination of the value chain. Issues that had to be clarified in the process ranged from the equitable distribution of profits among the strategic partners, to specific questions of product development, such as the prioritization of environmentally friendly packaging. In the literature, such a common understanding is referred to as a shared mental model, and is assumed to be essential for working effectively in 
groups (Langan-Fox et al. 2000; Senge 1990). Constructing shared knowledge and understanding is also described as crucial for supporting sustainability transitions in agri-food systems (Coughlan et al. 2016; Peterson 2009). Peterson (2009) argues that the responsiveness and efficiency of agrifood chains are directly linked to their capacity for creating knowledge within networks of relevant stakeholders.

When reflecting on the process that led to the founding of a joint enterprise, participants particularly highlighted the benefits of bringing together different perspectives and fields of expertise:

We see that, for founding the company, we need the expertise of [proprietor of a food processing company] for the manufacturing and at the same time he cannot do it alone. He also needs our understanding of how the organic sector here in the region works. It is this interaction between the different partners that makes the new company what it is.

(Farmer A, in a workshop in 2020)

The decision making is different than on our farm. In the group, we first gather all opinions and experiences and create a common idea of what we want to do. [...] Discussing a topic together over a longer period of time and creating something new out of it-this way I have also learned a lot that I can build on with my own farm.

(Farmer B, in a workshop in 2020)

The latter quote also highlights how the collaborative learning process benefited the individual participants' work. Similarly, in their discussion of learning in networks, Coghlan and Coughlan (2015) describe two different levels of learning - away and at home. In their model, learning in networks involves the exploration of new knowledge and its implementation and exploitation in practice (Coghlan and Coughlan 2015; Coughlan et al. 2016). These learning activities are described as at home when they take place within organizations, and as away when they take place between organizations in a network. Results of the present study indicate that in learning value chains, exploration happens primarily in the network, while exploitation takes place both within individual organizations and among organizations, e.g., through the formation of new strategic partnerships or joint enterprises.

Lesson \#3: Shared knowledge and understanding is at the core of local agri-food value chains. It is built on learning both within individual organizations and among the various organizations that make up the value chain.

\section{Learning strategies}

Following Argyris's (1995) notion of organizational learning, the learning network was aimed at enabling its members to make informed decisions, to develop the capacity to implement them, and to monitor the outcomes. Learning activities were designed to generate reliable and valid information to give practitioners a better understanding of the organizational issues both in the value chain and in their individual companies. The outcomes of the process can be described in terms of single- and double-loop learning.

The study suggests that double-loop learning is beneficial to bringing about sustainable innovations in local agri-food chains. To enable this kind of learning, process facilitation encouraged participants to challenge both their current value chain practices and the underlying frames of reference that drive them through activities involving both inquiry and reflection. The learning and negotiation processes within the network also led members to reveal and question their values and assumptions, for example, with regard to ecological standards or fair business practices. Results that can be understood as outcomes of double-loop learning are realigned business strategies and newly established practices of joint production and marketing, e.g., the bundling of produce from multiple farms for joint marketing to retailers-a type of horizontal cooperation that had not been practiced before among the network actors. Another example is the formation of joint enterprises in which actors from different levels of the value chain collaborate vertically to create added value at the local level. Challenging existing assumptions, however, led individual participants to decide not to further participate in the value chain development, which can also be seen as an expression of informed decision making in the sense of double-loop learning. This is illustrated by the following quote:

We asked ourselves in which direction our operation should develop. In the business workshop, we realized that there was little point in getting into vegetable production. This became clear while working on the vision and plans for our operation.

(Farmer, reflecting on the outcome of a workshop in 2018)

Experiences from the study also underlined that local agrifood value chains are not built on double-loop learning alone. The development of effective value chain structures also required gradual improvement and adaption of established routines and practices, which is commonly associated with single-loop learning. In the learning network, single-loop learning was demonstrated in improved operational processes and production techniques, as well as in improved logistics and communication between value chain 
actors. The results suggest that both modes of organizational learning can be supported by practical experimentation, reflection, and activities of inquiry aimed at participants' tacit knowledge structures. Double-loop learning, however, requires deeper reflection and inquiry, which can only be gradually established through process facilitation.

Eshuis and Stuiver (2005) also noted that both single and double-loop learning are necessary when developing sustainable practices in agriculture. In addition, they describe "learning how to learn" as a third learning strategy (Eshuis and Stuiver 2005, p. 143). Similarly, Coghlan and Coughlan (2015) highlighted that as learning networks develop, participants become more experienced and structures emerge, in which the actors continue to learn in self-organized ways. In the present study, self-organized learning could only be seen to a limited extent, for example, in a group of practitioners that was formed for a trial in vegetable production and continued to exchange information on production techniques after the end of the facilitated intervention. According to Peterson (2009), learning value chains require structures that can facilitate the continuous generation of new knowledge to adapt to changing requirements and conditions. Such structures of continuous, self-organized learning still need to be established in the emerging value chain to ensure that its members will be able to respond effectively to changing circumstances in the long term.

Lesson \#4: To establish the new practices and partnerships needed to build a local agri-food value chain, actors should question existing routines and develop new ideas and visions. At the same time, it is also necessary to improve established practices and adapt them to new situations.

\section{Reflection on the action research process}

Through shared inquiry, experimentation, and reflection, action researchers and the other members of the network were involved in a collaborative learning process. Practitioners had the opportunity to explore and to address their issues, while the researchers learned more about the practical problems and the practitioners' actions and thinking processes in solving these. Action research, thereby, faces the challenge of balancing practical and scientific relevance. Shani and Coghlan (2019) propose four factors for reflecting on and evaluating the success of action research, namely the context of the action research study, the quality of relationships, the quality of the action research process itself, and the outcomes of the process.

To establish the context of an action research study, researchers need to build a thorough understanding of the environment in which their research takes place (Shani and Coghlan 2019). Action research in local value chains, therefore, requires insight into the specificities of the region and its agri-food sector. To establish this foundation for the present study, a year-long survey was conducted in which both the initial and the evolving situation of the value chain was continuously and systematically explored. The survey drew on the perspectives of different actors at all levels of the chain as well as that of other stakeholders in the agrifood system, including agricultural consultants and policy makers.

With regard to the quality of relationships, the results presented underline the importance of regular interactions between practitioners and facilitators. For example, research results were regularly presented and discussed within the network. This helped the practitioners to gain new insights about their own professional practice and that of others in the agri-food system in their region. It also enabled the researchers to rapidly validate their results. The quality of relationships in action research also benefits from the facilitators' ability to speak the language of practitioners, and the involvement of local stakeholders who are recognized and respected by practitioners. In the present study, this was achieved through the involvement of the organic agriculture advocacy group as a boundary organization and through the facilitators' professional backgrounds in agriculture and agribusiness.

Regarding the quality of the action research process itself, the challenge is to balance scientific rigor and relevance for practice. This is particularly pertinent when action research is conducted in socially complex real-life situations, which can lead to highly dynamic and messy research processes (e.g., Cook 2009; Méndez et al. 2017). The experience from the present study suggests that for action research in emerging value chains, this challenge can be addressed by dividing responsibilities within a facilitation team. If different members of the team each advocate scientific rigor and practical relevance, a balance can be found through continuous renegotiation in the joint planning and reflection activities of the action research process.

Despite these challenges, action research is beneficial for the exploration of emerging value chains, as it allows for data to be collected in action, and can help to reveal practitioners' theory-in-use. This enables the development of insights that would not be possible using other research methods. Furthermore, it was possible to integrate both specific questions from practitioners within the network into the research and bring in new knowledge gained from outside the network, e.g., through in-depth interviews with actors in other regions. Such knowledge then directly benefited the learning network. The balancing of research and practical relevance also ensured that the outcomes of the study met the dual requirements of action research: new academic knowledge about the field of study was generated 
and concrete improvements of the real world situation were achieved.

Lesson \#5: Action research can support organizational learning in emerging agri-food chains while also creating academic knowledge about the topic. Action researchers need to build a sound understanding of the context of the value chain, emphasize relationships among the stakeholders, and balance scientific rigor and practical relevance.

\section{Conclusions}

This paper provides a behind-the-scenes view of a learning value chain and illustrates how a network of practitioners and process facilitators worked together to bring about targeted change in a local agri-food system. To support and investigate the learning value chain, the present study applied an action research approach. This approach removed the separation between academic research and practical problem solving as it was designed to have a direct impact in the real world through a series of interventions. Thus, it was possible to rapidly apply and test new knowledge in practice. At the same time, academic knowledge was created that is relevant to practice, as it was derived from concrete issues identified by practitioners.

In this case study, the action research intervention took the form of process facilitation, which was designed to bring agri-food practitioners together and empower them to better exploit the potential for local value creation. Through process facilitation, a social space was created, in which the actors were encouraged to explore their issues, develop new ideas and new connections, and experiment with new practices.

The study's outcomes suggest that the collaborative learning process has helped practitioners to approach complex problems in a structured and analytical way, to question existing routines, to improve their professional practice, and to establish new ways of working together. More specifically, the activities of the learning network enabled individual practitioners and their respective organizations to build up capabilities in organic vegetable production, but also to better understand their own businesses' opportunities and challenges in the context of the local agri-food system. On an inter-organizational level, process facilitation helped to form new value chain collaborations and improve the coordination of value chain activities. As part of their involvement in the study, participants made concrete economic decisions for their organizations and implemented them, for example, by founding new value chain ventures or by investing in production machinery or facilities. The learning network supported them in making these decisions, but the associated economic risk is borne by the participants themselves.
Participation in the learning network was particularly helpful to those actors who were willing and able to actively engage in the process, embrace change in their own organizations, and commit the necessary time and resources. Towards the end of the action research project, the participants faced the question of how to sustain their collaborative learning activities. The network tries to ensure that practitioners continue to learn together, both self-organized and supported by other local organizations that could provide consulting services and social spaces in the region.

Knowledge created through action research is particular and situational (Coghlan 2011). The changes in practice achieved in this case study are therefore specific to the region and the actors involved. The results depended on the actors' capabilities and external circumstances in the region. Nevertheless, the lessons regarding the learning process can, in principle, be transferred to other contexts in which agrifood practitioners work together to address a particular issue. The approach described in this paper is suitable for challenges where there are no model solutions and the situation must be improved through shared learning and negotiation among stakeholders. Overall, the learning value chain can be understood as an example of transformational learning in an inter-organizational context. In a transformational learning network, participants jointly generate new knowledge to improve the situation of all participating organizations (Coghlan and Coughlan 2015; Peterson 2009). However, it is often difficult for small and medium-sized organizations in agri-food value chains to build the necessary capacity for cooperation and organizational learning without external support. This concerns both the development of the individual organizations through continuous learning, and the networking necessary to establish values-based partnerships with other organizations. The present study shows that process facilitators can address such issues by acting as intermediaries, providing resources and organizing the learning process. In this regard, the present study underlines the importance of process facilitators in transformations towards more sustainable local agri-food systems.

Acknowledgements The authors would like to thank the members of the facilitation team and the value chain actors involved for their commitment and feedback throughout the action research process. They greatly inspired this research, shared valuable insights, and made the learning and change process possible.

Funding Open Access funding enabled and organized by Projekt DEAL. Funding for the study was provided by the European Agricultural Fund for Rural Development (EAFRD) in the framework of the European Innovation Partnership (EIP-Agri) and by the Federal State of Brandenburg, Germany. 


\section{Declarations}

Conflict of interest The authors declare that they have no conflicts of interest regarding this publication.

Informed consent All persons and organizations involved in the production of this publication are informed and familiar with the provided results and this publication. The participation of value chain actors in the action research study is based on their explicit consent.

Open Access This article is licensed under a Creative Commons Attribution 4.0 International License, which permits use, sharing, adaptation, distribution and reproduction in any medium or format, as long as you give appropriate credit to the original author(s) and the source, provide a link to the Creative Commons licence, and indicate if changes were made. The images or other third party material in this article are included in the article's Creative Commons licence, unless indicated otherwise in a credit line to the material. If material is not included in the article's Creative Commons licence and your intended use is not permitted by statutory regulation or exceeds the permitted use, you will need to obtain permission directly from the copyright holder. To view a copy of this licence, visit http://creativecommons.org/licenses/by/4.0/.

\section{References}

Agogué, M., E. Berthet, T. Fredberg, P. Le. Masson, B. Segrestin, M. Stoetzel, M. Wiener, and A. Yström. 2017. Explicating the role of innovation intermediaries in the "unknown": A contingency approach. Journal of Strategy and Management 10 (1): 19-39.

Argyris, C. 1995. Action science and organizational learning. Journal of Managerial Psychology 10 (6): 20-26.

Argyris, C., and D.A. Schön. 1996. Organizational learning II. Theory, method, and practice. Reading, Pennsylvania: Addison-Wesley Publishing.

Argyris, C., and D.A. Schön. 1989. Participatory action research and action science compared. American Behavioural Scientist 32 (5): 612-623.

Batie, S.S. 2008. Wicked problems and applied economics. American Journal of Agricultural Economics 90 (5): 1176-1191.

Bitsch, V. 2005. Qualitative research: A grounded theory example and evaluation criteria. Journal of Agribusiness 23 (1): 75-91.

Block, D.R., M. Thompson, J. Euken, T. Liquori, F. Fear, and S. Baldwin. 2008. Engagement for transformation: Value webs for local food system development. Agriculture and Human Values 25: 379-388.

Boström, M., E. Andersson, M. Berg, K. Gustafsson, E. Gustavsson, E. Hysing, R. Lidskog, E. Löfmarck, M. Ojala, J. Olsson, B.E. Singleton, S. Svenberg, Y. Uggla, and J. Öhman. 2018. Conditions for transformative learning for sustainable development: A theoretical review and approach. Sustainability 10 (12): 4479.

Bradbury H. 2015. Introduction: How to situate and define action research. In The Sage handbook of action research, ed. H. Bradbury, 3rd edition, 1-9. London, UK: Sage Publications.

Braun, C.L., M. Rombach, A.M. Häring, and V. Bitsch. 2018. A local gap in sustainable food procurement: Organic vegetables in Berlin's school meals. Sustainability 10 (11): 4245

Conner, D.S., G. Abate, T. Liquori, M.W. Hamm, and H.C. Peterson. 2010. Prospects for more healthful, local, and sustainably produced food in school meals. Journal of Hunger \& Environmental Nutrition 5 (4): 416-433.
Cook, T. 2009. The purpose of mess in action research: Building rigour though a messy turn. Educational Action Research 17 (2): $277-291$.

Corbin, J., and A. Strauss. 2015. Basics of qualitative research: Techniques and procedures for developing grounded theory, 4th ed. Thousand Oaks, CA: Sage Publications.

Coghlan, D. 2011. Action research: Exploring perspectives on a philosophy of practical knowing. Academy of Management Annals 5 (1): 53-87.

Coghlan, D., and P. Coughlan. 2015. Effecting change and learning in networks through network action learning. The Journal of Applied Behavioral Science 51 (3): 375-400.

Coughlan, P., D. Coghlan, D. O'Leary, C. Rigg, and D. Barrett. 2016. Supporting sustainability through developing a learning network among traditional food producers: Applications of action learning. In Organizing supply chain processes for sustainable innovation in the agri-food industry, ed. R. Cagliano, F.F.A. Caniato, and C.G. Worley, 59-81. Emerald: Bingley.

Doernberg, A., I. Zasada, K. Bruszewska, B. Skoczowski, and A. Piorr. 2016. Potentials and limitations of regional organic food supply: A qualitative analysis of two food chain types in the Berlin metropolitan region. Sustainability 8: 1125.

Eden, C., and C. Huxham. 1996. Action research for management research. British Journal of Management 7 (1): 75-86.

Eshuis, J., and M. Stuiver. 2005. Learning in context through conflict and alignment: Farmers and scientists in search of sustainable agriculture. Agriculture and Human Values 22: 137-148.

Friese, S. 2019. Qualitative data analysis with ATLAS.ti. London: Sage Publications.

Gentner, D., and A.L. Stevens. 2014. Mental models. New York: Psychology Press.

Glaser, B.G., and A.L. Strauss. 1967. The discovery of grounded theory. Strategies for qualitative research. New Brunswick, NJ: Aldine Transaction.

Guzmán, G.I., D. López, L. Román, and A.M. Alonso. 2013. Participatory action research in agroecology: Building local organic food networks in Spain. Agroecology and Sustainable Food Systems 37 (1): 127-146.

Hale, C.R. 2001. What is activist research. Social Science Research Council 2 (1-2): 13-15.

Holmqvist, M. 2003. A dynamic model of intra-and interorganizational learning. Organization Studies 24 (1): 95-123.

Howells, J. 2006. Intermediation and the role of intermediaries in innovation. Research Policy 35 (5): 715-728.

Huxham, C. 2003. Action research as a methodology for theory development. Policy \& Politics 31 (2): 239-248.

Ingram, J., P. Gaskell, J. Mills, and J.C. Dwyer. 2020. How do we enact co-innovation with stakeholders in agricultural research projects? Managing the complex interplay between contextual and facilitation processes. Journal of Rural Studies 78: 65-77.

Inman, A., M. Winter, R. Wheeler, E. Vrain, A. Lovett, A. Collins, I. Jones, P. Johnes, and W. Cleasby. 2018. An exploration of individual, social and material factors influencing water pollution mitigation behaviours within the farming community. Land Use Policy 70: 16-26.

Kanda, W., M. Kuisma, P. Kivimaa, and O. Hjelm. 2020. Conceptualising the systemic activities of intermediaries in sustainability transitions. Environmental Innovation and Societal Transitions 36: 449-465.

Kivimaa, P., W. Boon, S. Hyysalo, and L. Klerkx. 2019. Towards a typology of intermediaries in sustainability transitions: A systematic review and a research agenda. Research Policy 48 (4): 1062-1075.

Klerkx, L., and C. Leeuwis. 2009. Establishment and embedding of innovation brokers at different innovation system levels: Insights 
from the Dutch agricultural sector. Technological Forecasting and Social Change 76 (6): 849-860.

Langan-Fox, J., S. Code, and K. Langfield-Smith. 2000. Team mental models: Techniques, methods, and analytic approaches. Human Factors 42 (2): 242-271.

Lewin, K. 1946. Action research and minority problems. Journal of Social Issues 2 (4): 34-46.

Melin, M., and H. Barth. 2018. Lean in Swedish agriculture: Strategic and operational perspectives. Production Planning \& Control 29 (10): 845-855.

Méndez, V.E., M. Caswell, S.R. Gliessman, and R. Cohen. 2017. Integrating agroecology and participatory action research (PAR): Lessons from Central America. Sustainability 9 (5): 705.

Moschitz, H., D. Roep, G. Brunori, and T. Tisenkopfs. 2015. Learning and innovation networks for sustainable agriculture: Processes of co-evolution, joint reflection and facilitation. The Journal of Agricultural Education and Extension 21 (1): 1-11.

Peterson, H.C. 2009. Transformational supply chains and the 'wicked problem' of sustainability: Aligning knowledge, innovation, entrepreneurship, and leadership. Journal on Chain and Network Science 9 (2): 71-82.

Peterson, H.C. 2011. An epistemology for agribusiness: Peers, methods and engagement in the agri-food bio system. International Food and Agribusiness Management Review 14: 11-26.

Richardson, R., and E.H. Kramer. 2006. Abduction as the type of inference that characterizes the development of a grounded theory. Qualitative Research 6 (4): 497-513.

Schein, E.H. 1995. Process consultation, action research and clinical inquiry: Are they the same? Journal of Managerial Psychology 10 (6): 14-19.

Schein, E.H. 1996. Kurt Lewin's change theory in the field and in the classroom: Notes toward a model of managed learning. Systems Practice 9 (1): 27-47.

Schein, E.H. 1997. The concept of "client" from a process consultation perspective. Journal of Organizational Change Management 10 (3): 202-216.

Schön, D.A. 1983. Reflective practitioner: How professionals think in action. New York: BasicBooks.

Senge, P. 1990. The fifth discipline: The art and practice of the learning organization. Sydney: Random House.

Shani, A.B., and D. Coghlan. 2019. Action research in business and management: A reflective review. Action Research. 1-24.

Stevenson, G.W., K. Clancy, R. King, L. Lev, M. Ostrom, and S. Smith. 2011. Midscale food value chains: An introduction. Journal of Agriculture, Food Systems, and Community Development 1 (4): 27-34.

Swords, A. 2019. Action research on organizational change with the Food Bank of the Southern Tier: A regional food bank's efforts to move beyond charity. Agriculture and Human Values 36: 849-865.
Tengberg, A., and S. Valencia. 2018. Integrated approaches to natural resources management-Theory and practice. Land Degradation \& Development 29 (6): 1845-1857.

Vangen, S., and C. Huxham. 2003. Nurturing collaborative relations: Building trust in interorganizational collaboration. The Journal of Applied Behavioral Science 39 (1): 5-31.

Whyte, W.F. 1991. Participatory strategies in agricultural research and development. In Participatory action research, ed. W.F. Whyte, 169-178. Newbury Park, CA: Sage Publications.

Publisher's Note Springer Nature remains neutral with regard to jurisdictional claims in published maps and institutional affiliations.

Charis Linda Braun is a research assistant at the University for Sustainable Development Eberswalde Germany) and a PhD candidate at the Chair of Economics of Horticulture and Landscaping at Technical University of Munich (Germany). Her research focuses on sustainable innovation and change processes in agri-food systems. She holds a B.Sc. in Nutrition Science and Food Economics from the University of Giessen (Germany), and a M.Sc. in Management in Organic Agriculture from Eberswalde University for Sustainable Development (Germany) and the Humboldt University of Berlin (Germany).

Vera Bitsch conducts research in the fields of sustainability in agricultural value chains and agribusiness management. She graduated from Leibniz University of Hannover, Germany, in horticultural sciences. Her doctoral degree in horticultural sciences with an economics and management focus and habilitation (further qualification required for professorships in Germany) in agricultural economics were also awarded by University of Hannover. Before accepting the chair position at Technical University of Munich, she held a professorship at Michigan State University (U.S.A.), for ten years.

Anna Maria Häring research focuses on strategic business development in the food and farming sector, the assessment of agricultural and rural development policies and innovation processes in rural areas. Häring has worked at Hohenheim University (Germany), Ohio State University (U.S.A.), the Centro Internacional de Agricultura Tropical (Columbia), and she was a visiting research fellow at the International Food Policy Research Institute (U.S.A.). She gained her M.Sc. from Ohio State University (U.S.A.) and her doctorate degree in agricultural economics from Hohenheim University (Germany). 